\title{
Entre rodas de dança e coreografias: notas para um pensamento dançarino
}

\author{
Mg. Felipe Machado \\ Doutorando em Literatura, Cultura e Contemporaneidade pela \\ Pontifícia Universidade Católica do Rio de Janeiro (PUC-Rio) \\ felipewircker@gmail.com \\ (Recibido 18/10. Aceptado 18/11/2014)
}

\section{Resumo}

O presente artigo pretende abordar questões acerca das relações raciais no Brasil através da problematização da centralidade do pensamento ocidental e da branquitude enquanto espaço privilegiado de enunciação, enfatizando modos de pensar que privilegiem epistemologias e filosofias não ocidentais, bem como os estudos pós-coloniais, descoloniais e o pensamento contemporâneo que põe em perspectiva crítica a ocidentalidade. Para isso, parte da dança e coreografia como noções profícuas a um pensamento sempre em movimento que busque o dissenso e as tensões em detrimento do apaziguamento das relações sociais desiguais.

Palavras-chave: dança, corpo, pós-colonialidade, afroperspectivismo, branquitude.

\section{Dances and choreographies: notes for a thought in movement}

\begin{abstract}
This article aims to broach issues about racial relations in Brazil by questioning the centricity of western thought and whiteness as privileged fields of speech and enunciation, highlighting and prioritizing ways of thinking, epistemologies and non-Western philosophies, as well as postcolonial and decolonization studies and contemporary thought that put the western culture into a critical perspective. In order to achieve this proposal, the article takes the dance and choreography as profitable notions for a thought that is always in movement, which seeks dissent and tensions over the appeasement of unequal social relations.
\end{abstract}

Keywords: dance, body, post colonialism, African perspective, whiteness.

Este trabalho se insere em um caminho, uma caminhada. Porém, se é difícil determinar um ponto de partida, o é ainda mais pensar em um ponto de chegada. Limito-me a ensaiar uma coreografia, expondo algumas notas, traços, ou gestos de um possível pensamento que se quer dançarino. Assim, é inevitável que aqui eu me inscreva, pedindo licença para me referir em primeira pessoa nesse começo. E, evocando o movimento, sempre e já indissociável do pensamento, começo em uma roda de jongo. No documentário Saravá Jongueiro, Mestre Darcy do Jongo, a certa altura, faz o seguinte comentário:

E um cara que tem o ritmo na mão, ele domina o ritmo. Certo? Se algum aluno meu dançar jongo atravessado, eu posso não falar nada, eu sei que ele dançou atravessado. Eu, sem ficar doutor, eu sou formado na universidade do morro, da vida. Infelizmente, dentro das universidades, não está o suco das tradições populares. As tradições populares, elas são com seus mestres originais mesmo, como eu sou'.

A citação de Mestre Darcy nos traz algumas questões, das quais gostaria de destacar algumas: a primeira é a de que o saber não está restrito ao âmbito da academia. A segunda, a de uma supremacia do saber produzido na academia - o conhecimento dito científico - que se coloca hierarquicamente superior a outros saberes

1 Saravá Jongueiro. Direção: Luisa Pitanga, Bianca Brandão e Cecília de Mendonça. Brasil: 2003, 15min. Disponível em: http:// vimeo.com/8745821.

Machado, F. Entre rodas de dança e coreografias: notas para um 
(mesmo quando se reconhece que não há um modo de saber único). Desde já, o que se pode destacar como derivado dessas questões e que se insere no lamento de Mestre Darcy é a urgência de desierarquizar os modos de saber e destituir a supremacia do conhecimento científico. Isso pode se dar tanto por uma expansão do entendimento de ciência (o que é igualmente problemático uma vez que mantém sob a chancela de "ciência" aquilo que é ou busca ser legitimado como conhecimento) quanto por uma revisão histórica que permite constatar com mais nitidez as contingências que levaram a essa hierarquia para, assim, desmontá-la.

A supremacia do saber científico, acadêmico, é também a do saber ocidental (ou dos saberes ocidentais) e remete diretamente ao projeto moderno de colonização levado a cabo por países europeus - que persiste, ainda, sob outras formas, como essa destacada. Mesmo as narrativas históricas acerca desse processo de dominação ainda estão, no senso comum, arraigadas ao ponto de vista do Ocidente. Cabe lembrar, porém, que o próprio termo "Ocidente" é uma construção que tem como base o contraponto não ocidental, como o Oriente, a África e as Américas. Tais termos, antes de lugares geopolíticos naturalizados, mostram-se enquanto noções forjadas que se inserem na tentativa de compreender "o Outro" - compreender tanto no sentido de adaptálo a um código inteligível em uma determinada cultura, quanto no sentido de conter, confinar -; este Outro também, por sua vez, enquanto conceito criado que se insere em numerosos pares binários inerentes a este conhecimento que o denomina (tais como eu/outro, sujeito/objeto, humano/animal, corpo/espírito, corpo/ pensamento, pensamento/vida, natureza/cultura etc.). Nesse sentido, a etnologia e a antropologia são indissociáveis do projeto colonial. Entretanto, inflexões recentes nessas áreas do saber têm buscado desvincular essas disciplinas de um corolário colonizador.

No que tange a uma revisão histórica, inclusive da história das ciências, por exemplo, ela tem sido feita especialmente em campos disciplinares das ciências humanas com o intuito de descentrar o Ocidente enquanto "berço" ou origem do conhecimento tanto filosófico quanto científico, mostrando, por exemplo, como inúmeros saberes foram expropriados e usurpados no processo moderno de colonização de povos africanos e ameríndios, tais como técnicas de metalurgia e agricultura (Barbosa, 2008, 2010; Hountondji, 2008; Meneses, 2010; Ramose, 2011).

Neste sentido, é importante sublinhar que a hierarquização dos saberes é indissociável das teorias racistas e racialistas que foram desenvolvidas com afinco pela ciência moderna (seja pela biomedicina, psiquiatria, sociologia ou filosofia) sobretudo no século XIX e início do século XX, que teve como expressões mais radicais os regimes nazi-fascistas e as políticas de eugenia. Assim, uma das vias pelas quais opera o racismo é a de deslegitimação e desvalorização dos saberes de sociedades não ocidentais, isto é, saberes não centrados no conhecimento de matriz europeia.

Cabe ressaltar, todavia, que, após a Segunda Guerra, com o evidente fracasso do pensamento humanista europeu, o questionamento de dentro mesmo da filosofia ocidental tomou força, vide a crítica ao humanismo levada a cabo por filósofos como Jean-Paul Sartre e mesmo Martin Heidegger (1967), apesar de sua ligação com o regime nazista na Alemanha, bem como no pensamento estruturalista, através do questionamento da centralidade e da autonomia do Sujeito enquanto conceito filosófico, especialmente pelas vias da linguística, da psicanálise e da sociologia. A partir dos anos setenta, esse modo de pensar estruturalista foi também problematizado por outras análises que punham de vez em xeque a supremacia da ocidentalidade - tais como as de Michel Foucault, Jacques Derrida, Gilles Deleuze, em campos que transitam entre a historiografia, a antropologia, a sociologia, a linguagem e a filosofia.

Nas décadas de setenta e oitenta, fora da academia francesa, mas dialogando com ela, a produção acadêmica anglo-saxã viu surgir os estudos pós-coloniais e descoloniais concomitante à efervescência dos Estudos Culturais, dos quais Edward Said, Stuart Hall e Homi K. Bhabha são alguns dos nomes mais significativos. Também surgia, nos Estados Unidos, os chamados Estudos Subalternos ou da Subalternidade, encabeçados por pesquisadoras/es e pensadoras/es como Gayatri Chakravorty Spivak e fortemente ancorados na crítica desconstrucionista (se é que uma crítica desconstrucionista pode servir de porto; de todo modo, tal abertura crítica fomentou os questionamentos levantados pelos estudos da subalternidade). Enquanto oriundos de excolônias, Said, Hall, Bhabha e Spivak, entre outros, punham em questão a hegemonia do pensamento ocidental e a maneira como este estruturou sociedades, através do projeto colonial, em que os discursos e sistemas de pensamento que não fizessem parte dessa epistemologia não encontrariam espaço ou seriam deslegitimados enquanto modos de saber e de conhecimento, "violência epistêmica" (Spivak, 2010) que fomentou uma ocidentalização do mundo e a primazia do Ocidente. Esta prática veio a ser cunhada de "epistemicídio" no âmbito 
dos estudos pós-coloniais, isto é, o homicídio de epistemes não ocidentais pela negação de seu valor enquanto maneiras de conhecer e conceber o mundo, bem como de pensar/viver.

É inevitável, porém, falar em uma crítica ao ponto de vista da modernidade no cerne do próprio pensamento ocidental sem mencionar outros filósofos que, antes do fim da Segunda Guerra, já haviam levado a cabo uma crítica ao humanismo, tais como Friedrich Nietzsche. A crítica nietzscheana se insere em um escopo mais amplo de uma crítica ao antropocentrismo inerente ao modo de pensar em questão, que estaria irredutivelmente ligado ao pensamento humanista, ou aos humanismos que o Ocidente produziu. Contudo, foi no humanismo moderno, que, de fato, pela primeira vez, como aponta Foucault (2007), "o Homem" torna-se a figura central da cultura e do pensamento. No caso, "o Homem" corresponderia a um modelo de humanidade que se caracteriza pelos elementos "macho branco heterossexual carnívoro de classe média habitante das cidades", certamente, portanto, de matriz europeia; de modo que o que não estivesse inserido nessa concepção de humano estaria à margem, ou mesmo excluído da categoria de humanidade, fortemente calcada nas noções de raça, sexo, sexualidade, classe social, e forjada por um conjunto de práticas discursivas que atravessam diversos setores das sociedades e dos Estados modernos. Sabemos como isso foi usado como instrumento de colonização - não só de inúmeros povos, mas também dos corpos, e do próprio "corpo ocidental". Neste sentido, o não ocidental seria o não branco.

Nietzsche, porém, defendia uma irredutibilidade do caráter antropocêntrico do pensamento, afirmando que "não podemos enxergar além de nossa esquina" (2001:278). Criticava, assim, a pretensão de um olhar completamente livre de uma perspectiva epistemológica antropocêntrica, sem apontar, todavia, a perspectiva humana como a única possível, ou mesmo como superior. Para o filósofo, não haveria como separar a perspectiva humana de uma perspectiva antropocêntrica porque não há como separar corpo e pensamento, uma vez que a percepção do mundo passa pelo corpo e pelas relações que se estabelece com ele. No entanto, cabe ressaltar que essa referência à perspectiva demasiado humana da cultura ocidental de então não pode ser universalizada.

Posto isto, poderia aqui debruçar-me mais extensamente sobre a noção de perspectivismo, como a de "perspectivismo ameríndio" proposta por Eduardo Viveiros de Castro (2011), ou sobre os estudos de Carlos Castaneda acerca do pensamento e do modo de vida do xamã yaqui Don Juan; no entanto, fica para um desdobramento futuro. Cabe mencionar, contudo, que Viveiros de Castro mostrou como em epistemologias e cosmovisões de diferentes povos ameríndios esse pensamento "do homem", centrado no "humano" não se dá como na cultura ocidental, isto é, há um entendimento inteiramente distinto não apenas sobre o humano, como também sobre a relação entre o humano e os viventes que chamamos "animais", no qual assume-se que há uma multiplicidade de perspectivas que não podem ser classificadas e hierarquizadas a partir de uma única possibilidade interpretativa (nota-se como é complicado referir-se a culturas não ocidentais nos termos desta).

Viveiros de Castro, por sua vez, inspira-se largamente em Oswald de Andrade (2011), que, com otimismo e afirmação invejáveis, já apontava o crepúsculo da burguesia e da sociedade capitalista e patriarcal, bem como da hegemonia da filosofia ocidental, vislumbrando "uma filosofia que está para ser feita" e que teria como paradigma a valorização do pensamento antropofágico de matrizes indígenas ou ameríndias - a despeito, diga-se, dos preconceitos que carregavam os termos por ele usados, como "primitivo".

Mais recentemente, na linha de um pensamento perspectivista e em uma encruzilhada com os estudos da afrocentricidade, o filósofo Renato Noguera (2011) propõe um pensamento afroperspectivista. A afrocentricidade se oferece como um paradigma epistemológico que guia um recorte teórico-crítico. O que os estudos da afrocentricidade defendem é que, da mesma forma como a cultura ocidental não se restringe ao território geopolítico europeu, a cultura africana não se refere a um recorte geográfico, mas teórico-epistemológico, buscando uma reapropriação e ressignificação da noção de África. Ao optar-se por uma perspectiva afrocêntrica, afirma-se o pensamento das culturas de matriz africana como visões de mundo e sistemas de pensamento que tensionam com o da modernidade colonial ${ }^{2}$. Assim, a afrocentricidade vem a problematizar o racismo estrutural inerente à história "universal" eurocêntrica, o lugar geopolítico de enunciação da produção de conhecimento, da eurocentricidade como campo epistêmico que define o que é válido como conhecimento e pensamento e o que não é, ressaltando o caráter político do projeto intelectual-acadêmico e deixando manifesto que tanto a narrativa histórica quanto a produção de pensamento e conhecimento não são discursos desprovidos de uma

2 "Matriz africana deve ser entendida aqui como uma expressão 'plural', isto é, ela designa um conjunto de africanidades, nunca se trata de uma homogeneidade mítica" (Noguera, 2011 9, grifo do autor).

Machado, F. Entre rodas de dança e coreografias: notas para um 
perspectiva racial, sexual, de gênero e de classe ${ }^{3}$. Contudo, a afrocentricidade tampouco se constitui como um discurso monolítico, sugerindo uma simples troca de paradigma e colocando-se em oposição ao pensamento ocidental eurocentrado; mas defende o protagonismo de perspectivas epistemológicas não ocidentais sem pretender, contudo, homogeneizá-las.

No caso de uma filosofia afroperspectivista, Noguera inspira-se no pensamento de Gilles Deleuze e Félix Guattari (2010) quando defendem que a função da filosofia é criar conceitos, e que os conceitos não são meras abstrações, mas dizem respeito a problemas, sendo preciso, pois, criar conceitos novos para novos problemas. Valendo-se também da concepção de intercessores em Deleuze (2010), Noguera toma como intercessores elementos da cultura afro-brasileira e de culturas africanas, bem como orixás, voduns, inquices, entidades, animais ligados à liturgia do candomblé, e personagens minoritários como o malandro, o vagabundo, o sem-teto e a criança de rua, produzindo inúmeros novos conceitos e personagens conceituais extremamente profícuos para se pensar os problemas aos quais correspondem ou ao plano de imanência sobre o qual estão "assentados", sem, no entanto, ancorar-se em noções paralisadoras de identidade:

[A] raça invocada pela filosofia afroperspectivista tem muitos nomes; mas, todos são melanodérmicos num sentido bastante superficial que não se restringe a cor da pele. O mais importante é que os afetos, os devires e as potências sejam negras, isto é, as perspectivas são em favor da diferença num sentido radical. (Noguera, 2011 5)

Assim, "a filosofia afroperspectivista nos convoca para acontecimentos negros, acontecimentos femininos, acontecimentos infantis, acontecimentos animais; ela só pode ser entrevistada a partir desses acontecimentos e outros do mesmo 'gênero', de clivagens próximas" (Noguera, 2011 3); isto é, acontecimentos, pode-se dizer, minoritários ${ }^{4}$, que convocam e configuram uma imagem do pensamento operante pela diferença. Referindo-se à noção de imagem do pensamento, Noguera afirma que

[a] filosofia afroperspectivista está assentada sobre uma imagem do pensamento que pode ser apresentada em três teses básicas: 1a) Pensar é movimentação, todo pensamento é um movimento que ao invés de buscar a Verdade e se opor ao falso, busca a manutenção do movimento; 2a) O pensamento é sempre uma incorporação, só é possível pensar através do corpo; 3a) A coreografia e o drible são os ingredientes que tornam possível alcançar o alvo do pensamento: manter a si mesmo em movimento. (20116)

Percebe-se, portanto, como o filósofo não se restringe a simplesmente reler ou reformular com termos próximos as noções propostas por Deleuze e Guattari, mas de fato apropria-se delas para a concepção e a forja de novos conceitos que dizem respeito a questões de um pensamento afroperspectivista, sobretudo no Brasil. Neste sentido, nota-se, também, como ele faz uso de um vocabulário incomum à tradição filosófica ocidental, porém bastante habitual às religiões afro-brasileiras, não só desnaturalizando a crença na origem ocidental da filosofia como também tomando o candomblé como sistema de pensamento, ou perspectiva epistêmica - gesto, por sua vez, que, segundo Noguera, se refere a dois problemas da filosofia afroperspectivista que o conceito de "denegrir" busca dar conta:

[D]enegrir é um conceito filosófico afroperspectivista que significa enegrecer, assumir versões e perspectivas que não são hegemônicas, considerar a relevância das matrizes africanas para o pensamento filosófico, investigar em bases epistêmicas negro-africanas, dialogar, apresentar e comentar trabalhos filosóficos africanos, abordar filosoficamente temáticas como: relações etnicorraciais, epistemicídio dos saberes de matriz negro-africana, racismo anti-negro, branquitude e hegemonia dos parâmetros ocidentais no âmbito político e estético. (Noguera, 2011 15)

\footnotetext{
3 Uso, aqui, os termos "conhecimento" e "pensamento" ciente e consoante à distinção proposta por Deleuze (s/d) em Nietzsche e a filosofia, a partir de uma leitura do filósofo alemão, segundo a qual o conhecimento estaria subordinado e determinada visão de mundo que o limita, ao passo que o pensamento pode estar, ou não, restrito e subordinado a esta concepção do conhecimento.

4 Tal como o propõem Deleuze e Guattari, isto é, das minorias não enquanto grupos supostamente menores em termos quantitativos, senão como aquilo que se desvia ou não corresponde ao modelo majoritário: homem branco macho heterossexual de classe média habitante das cidades.
} 
Transvalorando um termo com uma forte carga racista, denegrir, portanto, não se refere nem à acepção negativa do senso comum, nem à defesa de uma identidade racial, senão à possibilidade de "reativar as forças próprias de um devir negro-africano" (Noguera, 2011 3).

A afrocentricidade e os estudos descoloniais colocam, ainda, outro problema que toca o debate em torno do espaço geopolítico da produção de conhecimento: diante da violência epistêmica usada como instrumento de dominação pelo discurso eurocentrado, torna-se necessário que os elementos e a história das culturas de matriz africana não sejam mais expropriados ${ }^{5}$ como o foram no processo de dominação, seja no âmbito acadêmico ou fora dele, para que não se reproduza a mesma violência colonial histórica. Diante disto, que relações e que tendências pode um pesquisador branco buscar diante do combate ao racismo institucional e da necessidade urgente de questionar seu lugar privilegiado? Como desierarquizar a diferença racial sem apagar as diferenças histórico-culturais e muito menos a violência da história política, econômica e social no Brasil? Certamente, na condução da justiça racial, que precisa ser reconhecida como uma dívida sócio-histórica, a branquitude não deve reivindicar posições de protagonismo, senão colocar-se como coadjuvante nesse processo.

Nos vemos, pois, diante do dever de rever toda uma narrativa histórica usada como instrumento de dominação e da oportunidade de criar uma ética e uma política, ou éticas e políticas que não sejam da ordem da dominação e da violência epistêmica. A criação, no espaço geopolítico brasileiro, de coletividades menos atreladas a identidades baseadas nos pressupostos do pensamento colonial (tais como os entendimentos modernos de raça, classe, gênero, sexo, sexualidade e nação), requer não apenas uma crítica à ocidentalidade, mas também a valorização de perspectivas epistemológicas não ocidentais como produções legítimas de pensamento e conhecimento, profícuas tanto no deslocamento e na desconstrução de certos pre(con)ceitos, quanto na criação de modos de vida que não se fundamentem nas hierarquias coloniais.

A respeito disso, também, as religiões de matriz africana têm muito a ensinar; assim como o perspectivismo ameríndio, a afirmação do pensamento de culturas afro-diaspóricas é imprescindível para se repensar as relações sociais no Brasil e as relações que atravessam distintas comunidades e coletividades, em seus aspectos ético, estético e político. Não presumo poder responder aqui às questões propostas, uma vez que trata-se de um caminho em curso, e tampouco tenho a pretensão de respondê-las definitivamente, senão de me guiar por elas, usá-las como impulsos para um pensamento sempre em movimento, na busca de possibilidades que não reproduzam relações de desigualdade e opressão.

No que concerne à branquitude, não se trata de colocar-se em um lugar de culpa, e tampouco resolve a noção de dívida. A dívida certamente existe, mas é, sobretudo, uma questão de responsabilidade para além da dívida. Primeiro porque a dívida nos dá a ideia de que pode ser quitada e, uma vez sanada, estaríamos "quites" e, pior, isentos de uma responsabilidade. A noção de responsabilidade incondicional nos coloca diante do problema de outra maneira. Por fim, é uma questão de gesto. Não há final estabelecível, um lugar para se acomodar, um telos universalizante ou totalizante das relações sociais. Ao contrário, cada vez que se acomoda é preciso movimentar-se novamente.

É preciso que uma certa produção desejante normativa seja alterada, mutada, transformada, uma vez que, em seu funcionamento, produz-se o desejo por diversas formas de preconceito - racismo, machismo, sexismo, homofobia - incitando-os constantemente. Esse desejo é sempre reatualizado e as consequências são catastróficas. Ele está, sem dúvidas, ligado ao sistema econômico capitalista que precisa dessa produção desejante para se retroalimentar. Não questionar esse processo - e não se questionar nesse processo, no caso da branquitude - já é inserir-se acriticamente no discurso dominante que o produz e que precisa do preconceito de categorias hierárquicas para operar.

Como lidar com a irreversibilidade do processo colonial e com esse agenciamento maquínico considerando-se, por exemplo, que nessa estrutura social, o pertencimento majoritário inevitavelmente coloca o indivíduo em posição de supremacia em uma hierarquia (seja por ser branco, homem, heterossexual e/ou de classes dominantes)? Neste sentido, é necessário criar interferências, curto-circuitos nesse sistema que alterem a produção desejante e as produções hegemônicas de sentido - do que é ser negro, branco, homem, mulher, homossexual,

5 Conforme levantado por integrantes do Movimento Negro no minicurso "Afrocentricidade e História", ministrado pelo Prof. Dr. Renato Noguera (UFRRJ) nos dias 4 e 5 de novembro de 2013, no IFCS-UFRJ promovido pelo Caderno Universitário de História durante o IX Encontro de Pesquisas de Graduação em História, reivindicando, assim, o protagonismo de pessoas negras na disseminação dos saberes ligados à diáspora africana. 
heterossexual etc - inventando ou atrelando-se a outras máquinas (como propuseram Deleuze e Guattari acerca das máquinas de guerra).

A noção de "entrecruzamento de opressões" proposta por bell hooks no âmbito do feminismo negro (apud Preciado, 2010 48), parece profícua para uma análise do estágio atual e para a criação de estratégias políticas não hegemônicas que privilegiem uma perspectiva intersecional, isto é, da articulação entre as políticas de classe, raça, gênero, sexo e sexualidade. A intersecionalidade não é uma soma de opressões ou posições subalternas (ou, mais especificamente, subalternizadas), mas supõe uma sobreposição, um entrecruzamento dessas diferenças que produzem posições distintas de acordo com essas interações ou confluências. Não se trata de somar as questões ou políticas de gênero, sexo, sexualidade, raça e classe ou simplesmente compreender as variáveis das opressões, mas de analisar esses espaços de sobreposição como processos constitutivos da modernidade colonial criando "estratégias de intersecionalidade política" (Crenshaw, 2002181 apud Preciado, 2006) que deslegitimem a "unidimensionalidade dos saberes produzidos pelas representações da modernidade sexo-colonial” (Preciado, 2006).

Apesar da opressão aos povos não brancos e do epistemicídio, porém, não se pode pressupor que o poder coIonial foi forte o suficiente para desmantelar as culturas e os sistemas de pensamento de matrizes africana e ameríndia no Brasil, o que, de certa forma, seria reiterar a supremacia do poder colonial e apostar que a dominação se deu sem resistências e foi passivamente assimilada.

Sob esse aspecto, cabe perguntar se seria possível, ainda, pensar a mestiçagem não mais como algo que acomode as relações raciais (sempre tensionadas), que não homogeneize e não atue como estratégia de dominação nas relações de poder, mas como um campo de tensões entre saberes, epistemologias e culturas distintas que coloque em questão os privilégios da branquitude e seu espaço no tecido social (econômico, político, cultural) do espaço geopolítico brasileiro. Isto requer, sem dúvida, uma concepção positiva da diferença como elemento afirmativo-criativo em detrimento do discurso apaziguador da mestiçagem usado pelas classes dominantes e pela branquitude como instrumento de manutenção das relações sócio-raciais no Brasil através de uma suposta "democracia racial".

Tal questionamento acerca da mestiçagem deriva de uma certa ambivalência, por exemplo, das relações de gênero e sexualidade que pode ser observada no Brasil: ao mesmo tempo em que as normas de gênero, sexo e sexualidade inerentes ao patriarcado e ao pensamento moderno ocidental prevalecem, também vazam o tempo todo, sendo permeadas por influências que não têm os mesmos fundamentos morais que a cultura judaico-cristã (muito pelo contrário) - oriundas, primordialmente, das culturas de matriz africana.

Sob esse aspecto, nota-se que a corporeidade de mexer o quadril aparece muito ligada à erotização e ao sexo, mas de maneiras e com intensidades de valoração moral variadas de acordo com pertencimentos distintos de raça, classe e região no país. Em que espaços e de que maneiras isso se dá seria algo a investigar com mais acuidade para tornar mais nítidas essas relações. De todo modo, o movimento de mexer o quadris permanece ainda atrelado a uma valoração moral que o coloca como vulgar, enquanto que em culturas não ocidentais pode ter outro valor, como mostra Sobonfu Somé, oriunda do povo dagara, em Burkina Fasso, e radicada nos Estados Unidos. Somé (2007) explica que em sua cultura o movimento dos quadris tem relação direta com a circulação de energia no corpo, de acordo com uma percepção espiritual (uma vez que não há oposição entre corpo e espírito como na cultura cristã).

Julian Henriques (2011), por sua vez, propõe um pensamento a partir e através do som. Criado na Inglaterra, mas descendente de jamaicanos, Henriques parte da música dub e reggae para pensar uma epistemologia do som, em lugar de uma epistemologia ancorada no logos, isto é, na palavra, e também na imagem (isto é, na visualidade), conforme a tradição ocidental. Por certo que isto não exclui logos e imagem, apenas recusa a supremacia desses elementos e os coloca em outro sistema de relações. Partindo de uma concepção do corpo como um jardim, ao invés do "corpo-máquina-orgânico-fisiológica", como quis a ciência moderna, ele se inspira em uma visão do corpo como chacras, fontes e circulação de energias e intensidades ${ }^{6}$. O pensamento pelo som tampouco exige uma primazia da audição sobre a visão, uma vez que, sendo os corpos sônicos, isto é, compostos de som, este não necessariamente se escuta - ele atravessa. Pensar pelo som é pensar por incorporação, por ingestão, é um pensamento corpóreo, com o corpo.

6 Conforme palestra "Visão sônica e imaginação auditiva", ministrada por Julian Henriques no Auditório do CFCH, Escola de Comunicação da UFRJ, no dia 17 de março de 2014. 
A concepção de Henriques se aproxima bastante da afroperspectiva proposta por Noguera, como visto acima, uma vez que o movimento, o som e o corpo (nos processos de incorporação) seriam cruciais na filosofia afroperspectivista. Um dinamismo do pensamento, de fato, "só pode ser expressado por práticas corpóreas de pensamento" (Henriques, 2011). Pode-se dizer que essa dinâmica atravessa e circula entre corpo individual e corpo coletivo, promovendo conexões, disrupções, desterritorializações e reterritorializações, desconfigurações e reconfigurações. Em lugar de um objeto do pensamento, encontram-se processos, acontecimentos. Tal concepção também remete ao pensamento de Deleuze e Guattari. Entretanto, na presente reflexão, buscou-se destacar como, de acordo com epistemologias não ocidentais, o pensamento enquanto movimento, dinamismo e fluxos intensamente ligados ao corpo, valorizando uma corporeidade que não se opõe à racionalidade, já era, de certa forma, um "paradigma”, fato que se dá a ver em manifestações afro-diaspóricas nas Américas, como é o caso do reggae e do dub jamaicanos, bem como das religiões de matriz africana.

Segundo Henriques, o som não é da ordem da representação, senão da apresentação. Assim pode-se pensar a dança, em especial as danças de matriz africana. No âmbito das religiões afro-brasileiras, por exemplo, a dança é um elemento crucial. Ela não está separada da cosmovisão inerente a esses sistemas de pensamento, uma vez que pares como corpo e espírito, corpo e pensamento não se dão como termos opositivos e descontínuos como na cultura ocidental de matriz cristã. É importante lembrar que até mesmo "o corpo" é uma criação do ocidente (Nancy, 2000). E quando falamos em corpo e dança talvez estejamos categorizando elementos que em culturas e epistemologias não ocidentais não são categorizáveis tal como a ocidentalidade os entende; assim, o faço como mero recurso de referência, como o dizer com essas palavras me impele a fazer.

A dança, portanto, faz parte de uma concepção muito maior de movimento que só pode ser pensada a partir das cosmologias respectivas, seja de matriz lorubá, Jeje, Efon, Bantu, Ijexá ou tantas outras. Em certo sentido, é como se dançar e caminhar fossem movimentos contíguos, como me foi observado em uma das primeiras aulas de dança afro?. Aqui me limito por evitar teorizar o candomblé, reduzir ou esquematizar o que não é esquematizável, mas também por não ter vivência e conhecimento suficientes para me arriscar a qualquer explicitação. Em suma, não se pode homogeneizar as concepções de dança e corpo, que, em culturas de matriz africana, por exemplo, vinculam-se a epistemologias e racionalidades que envolvem maneiras singulares de perceber/conhecer o mundo, impondo, inclusive, limites a esse conhecimento - não se pode compreender tudo, na dupla acepção do termo.

Perceber o candomblé e as culturas que o compõe como sistemas de pensamento, portanto, nos faz partir de certos pressupostos e nos coloca diante de determinada perspectiva que certamente tensionam com o que se constituiu como a ocidentalidade, além de fazer notar como o cristianismo se impôs enquanto cultura e o quanto o pensamento ocidental (bem como o processo de ocidentalização do mundo) está permeado pela moral judaico-cristã - como, aliás, apontara Nietzsche (2008). Assim, talvez seja possível desmontar o racismo de representações estereotipadas acerca do povo negro e de culturas afro-brasileiras, ou, mais amplamente, de epistemologias não ocidentais e não brancas no Brasil que envolvem concepções e vivências diversas de gênero e sexualidade, por exemplo.

Por hora encerro, buscando os passos de um pensamento em movimento, seguindo o que propõe Noguera acerca do pensamento como coreografia - este, por sua vez, menos uma sequência prédeterminada de movimentos do que um movimento constante de um pensamento que não se deixa estancar. Um pensamento através do som, portanto, ou um pensamento dançarino, talvez me permita tornar esse fazer-pensar um exercício de escuta e aprendizado mais do que um acúmulo de saber - como ali, em uma roda de jongo.

\footnotetext{
7 A respeito de um pensamento a partir do som e das relações entre som e movimento, vale conferir o documentário Foli: Il n'y a pas de mouvement sans rythme. Direção: Thomas Roebers; Floris Leeuwenberg. Guiné, 2010, 11 min. Disponível em: https:// www.youtube.com/watch?v=IVPLluBygCY.
} 


\section{Referencias bibliográficas:}

Andrade, Oswald de (2011) A utopia antropofágica. São Paulo: Globo.

Asante, Molefi (2009) Afrocentricity. Publicado em 13/4/2009. http://www.asante.net/articles/1/ afrocentricity/

Barbosa, Muryatan S. (2008) Eurocentrismo, História e História da África. Sankofa. Revista de História da África e de Estudos da Diáspora Africana 1. Junho/2008.

---. (2010) História da África: ética e ciência. Sankofa. Revista de História da África e de Estudos da Diáspora Africana 3, 6, Dezembro/2010.

Bhabha, Homi K. (2005) O local da cultura. Belo Horizonte: Editora UFMG.

Calarco, Matthew (2008) Zoographies: the question of the animal from Heidegger to Derrida. New York: Columbia University Press.

Coelho, João Paulo Borges (2011) Notas em Torno da Representação Africana de África (ou alguns dilemas da historiografia africana). Representações de África e dos Africanos na História e Cultura - Séculos XV a XXI. Centro de História de Além-Mar faculdade de Ciências Sociais e Humanas/Universidade Nova de Lisboa Universidade dos Açores, Julho/2011.

Crenshaw, Kimberlé (2002) Documento para o encontro de especialistas em aspectos da discriminação racial relativos ao gênero. Revista Estudos Feministas. Florianópolis 10, 10 semestre 2002. 171-188.

Deleuze, Gilles (s/d) Nietzsche e a filosofia. Trad. António M. Magalhães. Porto: Rés.

---. (2010) Conversações. Trad. Peter Pál Pelbart. São Paulo: Ed. 34.

Deleuze, Gilles Guattari, Félix (1997) Mil Platôs: capitalismo e esquizofrenia, vol. 4. Trad. Suely Rolnik. São Paulo: Ed. 34.

---. (2010) O que é a filosofia? Trad. Bento Prado Jr e Alberto Alonso Muñoz. Rio de Janeiro: Ed. 34.

Duque-Estrada, Paulo Cesar (2005) Derrida e a crítica heideggeriana do humanismo. Nascimento, Evando, Org. (2005). Jacques Derrida: pensar a desconstrução. São Paulo: Estação Liberdade.

---. (2010) Derrida e o pensamento da desconstrução: o redimensionamento do sujeito. Cadernos IHU Ideias 8, 143, UNISINOS.

Fanon, Frantz (2008) Pele negra, máscaras brancas. Salvador: EDUFBA.

Foucault, Michel (1988) História da Sexualidade: A vontade de saber. Rio de Janeiro: Edições Graal.

---. (2007) As palavras e as coisas: Uma arqueologia das ciências humanas. Trad. Salma Tannus Muchail. São Paulo: Martins Fontes.

Hall, Stuart (2003) Da diáspora: identidades e mediações culturais. Belo Horizonte: Editora UFMG, 2003.

Heidegger, Martin (1967) Sobre o Humanismo. Trad. Emmanuel Carneiro Leão. Rio de Janeiro: Tempo Brasileiro.

Henriques, Julian (2011) Preamble: Thinking through sound. Sonic Bodies: Reggae Sound Systems, Performance Techniques Q Ways of Knowing. London: Bloomsbury Publishing.

Hountondji, Paulin J. (2008) Conhecimento de África, conhecimento de Africanos: Duas perspectivas sobre os Estudos Africanos. Revista Crítica de Ciências Sociais 8o, Março/2008. 149-160.

Meneses, Maria Paula (2010) Outras Vozes Existem, Outras vozes São Possíveis. Garcia, Regina Leite, org. (2010) Diálogos Cotidianos. Petrópolis, RJ: DP et Alii.

Nancy, Jean-Luc (2000) Corpus. Paris: Éditions Métailié.

Nietzsche, Friedrich (2001) A gaia ciência. Trad. Paulo César de Souza. São Paulo: Companhia das Letras.

---. (2008) Ecce Homo - como alguém se torna o que é. Trad. Paulo César de Souza. São Paulo: Companhia das Letras.

Noguera, Renato (2011) Denegrindo a filosofia: o pensamento como coreografia de conceitos afroperspectivistas. Griot - Revista de Filosofia 4.2 Dezembro/ 2011, Amargosa, Bahia - Brasil.

Preciado, B. (2006) Savoirs_Vampires@War. Multitudes Web. http://multitudes.samizdat.net/SavoirsVampires-War 
Ramose, M. B. (2011) Sobre a Legitimidade e o Estudo da Filosofia Africana. Ensaios Filosóficos 4. Outubro/2011.

Sartre, Jean-Paul (s/d) O existencialismo é um humanismo. Trad. Rita Correia Guedes. http://stoa.usp.br/ alexccarneiro/files/1/4529/sartre_exitencialismo_humanismo.pdf

Somé, Sobonfu (2007) O Espírito da Intimidade: ensinamentos ancestrais africanos sobre maneiras de se relacionar. São Paulo: Odysseus.

Spivak, Gayatri Chakravorty(2010) Pode o subalterno falar? Belo Horizonte: Editora UFMG.

Viveiros De Castro, Eduardo (2011) Perspectivismo e multinaturalismo na América indígena. A inconstância da alma selvagem - e outros ensaios de antropologia. São Paulo: Cosac Naify. 